\title{
Influence of Gradation on Resilient Modulus of High Plasticity Soil-Gravel Mixture
}

\author{
Chuang Liu, ${ }^{1,2}$ Tian-Zeng Ren, ${ }^{1}$ Rui Zhang $\mathbb{D}^{1,3}$ Qian-Feng Gao, ${ }^{1,3}$ and Jian-Long Zheng ${ }^{1,3}$ \\ ${ }^{1}$ School of Traffic \& Transport Engineering, Changsha University of Science \& Technology, Changsha, Hunan 410114, China \\ ${ }^{2}$ Department of Traffic and Transportation of Hainan Province, Haikou, Hainan 570204, China \\ ${ }^{3}$ National Engineering Laboratory for Highway Maintenance Technology, Changsha University of Science \& Technology, \\ Changsha, Hunan 410114, China \\ Correspondence should be addressed to Rui Zhang; zr@csust.edu.cn
}

Received 12 March 2020; Accepted 28 April 2020; Published 14 May 2020

Academic Editor: Fan Gu

Copyright (c) 2020 Chuang Liu et al. This is an open access article distributed under the Creative Commons Attribution License, which permits unrestricted use, distribution, and reproduction in any medium, provided the original work is properly cited.

\begin{abstract}
Because of low resilient modulus, high plasticity soil is often not allowed to fill road subgrades and is discarded as construction and demolition waste (CDW). To make use of the CDW, this study explored the possibility of improving high plasticity soil with gravel and examined the effect of gravel gradation on the resilient modulus of the soil-gravel mixture. A series of dynamic triaxial tests, tests of voids in coarse aggregate, and X-ray CT scans were carried out on high plasticity soil-gravel mixtures of different gravel contents and gravel gradation types. The test results show that there is a critical gravel content, that is, $44.1 \%$. When the gravel content is less than $44.1 \%$, the mixture shows a dense suspended structure and its modulus increases slowly with increasing gravel content. When the gravel content is greater than $44.1 \%$, the mixture exhibits a dense skeleton structure and the modulus increases rapidly as the gravel content rises. Moreover, as the gravel gradation tends to the lower type, coarse aggregates increase in quantity and contact each other to form a dense skeleton; thus, the modulus increases accordingly. As the gravel gradation approaches the upper type, coarse aggregates decrease in quantity and tend to suspend in the soil, so the modulus decreases. With the increase in contact number, the skeleton structure is continuously improved, and thus the modulus is enhanced progressively. The results indicate that the gravel mixing method with a gravel content of $40 \%-45 \%$ can effectively improve high plasticity soil and shows great environmental and economic benefits.
\end{abstract}

\section{Introduction}

High plasticity soil is one of the common special soils in highway construction. It is of high natural moisture content, high liquid limit, high plasticity index, etc. When high plasticity soil is directly used to fill road subgrades, the resilient modulus often could not satisfy the minimum requirement for pavement design [1, 2]. Thus, high plasticity soil is generally not a qualified subgrade filler and should be discarded as construction and demolition waste (CDW) [3]. However, this would cause high construction costs and go against environmental protections. In order to make use of the CDW, particular measures must be taken to improve high plasticity soil. The improvement measures basically include the chemical method and the physical method.
In the past few years, some studies have been carried out on the engineering characteristics of high plasticity soils improved by chemical methods. Lime is able to improve the physical and mechanical properties including the strength of high plasticity soil [4-8]. Nevertheless, with the increase of lime content, energy consumption and carbon dioxide emissions will greatly increase, which has a certain impact on the environment [9]. The addition of fly ash is also a feasible method but its improvement effect is not as good as that of quicklime [5]. Also, Portland cement can significantly improve the strength of high plasticity soil; however, it has little effect on some important properties such as the optimum moisture content $[5,10]$. Furthermore, soil stabilizer has a good effect on the strength improvement of high plasticity soil, but it needs a high requirement regarding construction 
$[11,12]$. The above chemical methods are not only uneconomical but also bad for the surrounding environment of highways.

Compared with chemical methods, gravel mixing, as a physical method, is much cheaper and more environmentally friendly. This method is widely used for improving high plasticity soils, such as expansive soil and other fine-grained soils [13-17]. For this reason, some laboratory tests were completed to study the mechanical behavior of high plasticity soil improved by adding gravel [18-20]. Bera [14] studied the influence of sand content (\%) on the liquid limit, plastic limit, and California bearing ratio (CBR) of a fine-grained soil. A nonlinear model was established to predict the maximum dry density and optimum moisture content of the gravel-soil mixture. $\mathrm{Wu}$ et al. [5] reported that the CBR value of high plasticity soil increases significantly and its crack resistance is improved after gravel mixing. Guo et al. [10] found that increasing sand content could considerably enhance the strength of high plasticity soil. Zhang et al. [17] stated that when the sand content is more than $30 \%$, the volume shrinkage rate can be reduced and the soil strength can be greatly increased. However, most of these studies went no further than the analysis of the physical and mechanical properties of improved high plasticity soils and gave little attention to the improvement mechanism.

There are many indexes, such as the liquid limit, plastic limit, CBR value, and compression index, for evaluating the improvement effect of high plasticity soils [5-8]. Additionally, the resilient modulus is a comprehensive property that can reflect the above indexes and is also a basic index for pavement design [21-25]. Therefore, it is appropriate to use resilient modulus to evaluate the improvement effect of high plasticity soils [26-28].

Similar to asphalt mixtures, gravel particles are either suspended in the mixture or in close contact with each other to form a skeleton structure when high plasticity soil is mixed with gravel. Some scholars have found that, for an asphalt mixture, the particle size and the number of contact points between coarse aggregates have a significant impact on its composition and structure, thus affecting its physical and mechanical properties and pavement performance [29-32]. These factors depend to a large extent on the aggregate gradation. Therefore, according to the skeleton structure analysis of asphalt mixtures, the influence of gradation on the resilient modulus of high plasticity soil-gravel mixture can be analyzed based on gravel content, particle size, and contact number.

In this study, several groups of samples with different gravel contents and gravel gradation types were prepared. Dynamic triaxial tests were conducted to determine the dynamic resilient modulus of the samples. Subsequently, the skeleton structure of the mixture and the contact characteristics of gravel particles were analyzed by testing the voids in coarse aggregate and conducting X-ray CT scans, respectively. The influence of gradation on the modulus of the soil-gravel mixture was studied from two aspects, that is, gravel content and gravel gradation type.

\section{Materials and Test Methods}

\subsection{Materials}

2.1.1. High Plasticity Soil. The high plasticity soil was collected from the ninth bid section of the Wanning-Yangpu expressway in Hainan Province, China. The basic physical properties of the soil were tested, as shown in Table 1 . The soil contained $60.3 \%$ fine particles $(<0.075 \mathrm{~mm})$, and its liquid limit was higher than $50 \%$. The natural moisture content was greater than the plastic limit and the optimum moisture content, so the soil was difficult to compact directly.

2.1.2. Gravel. The gravel used in this study was taken from Danzhou City, Hainan Province, China. Its basic physical properties are as follows: density $=2.06 \mathrm{~g} / \mathrm{cm}^{3}$, gravel $(>4.75 \mathrm{~mm})$ content $=57 \%$, sand $(0.075-4.75 \mathrm{~mm})$ content $=41.9 \%$, and silt and clay $(<0.075 \mathrm{~mm})$ content $=1.1 \%$. The grain groups and the gradation curve are presented in Figures 1 and 2, respectively. This material is classified as gravel in accordance with ASTM D2487-06 [33].

2.2. Test Methods. Dynamic triaxial tests, tests of voids in coarse aggregate, and X-ray CT scans were performed to explore the influence of gradation on the resilient modulus of high plasticity soil-gravel mixture.

\subsubsection{Selection of Gravel Content and Gravel Gradation.} In order to study the effect of gravel contents (i.e., the mass ratio of gravel to high plasticity soil) on the resilient modulus of high plasticity soil with gravel, five samples with different gravel contents (i.e., $30 \%, 35 \%, 40 \%, 45 \%$, and 50\%) and the same gravel gradation type (see Figure 2) were prepared.

On the other hand, the soil samples with a gravel content of $50 \%$ and four different gravel gradation types were considered to examine the influence of the gravel gradation type on the behavior of high plasticity soil-gravel mixture. Apart from the gravel gradation type (\#3) shown in Figure 2, three additional gravel gradation types (i.e., \#1, \#2, and \#4) were taken into account (Figure 3), referring to the literature [34].

2.2.2. Dynamic Triaxial Tests. Dynamic triaxial tests were carried out on the high plasticity soil-gravel mixture samples using the APS-Wille Geotechnik dynamic triaxial test system (Figure 4(a)). High plasticity soil and gravel were manually mixed for 5-8 min in a basin and then mechanically stirred for $10-20 \mathrm{~min}$ in a laboratory concrete mixer (Cangzhou Senzhong Testing Instrument, China) at a stirring rate of $100 \mathrm{r} / \mathrm{min}$ to obtain a homogeneous mixture. A certain amount of water was added during the stir to bring the moisture content of the mixture to the optimum value. The mixture samples were formed by compacting the mixture in a mold using a press machine. The samples had a diameter of $100 \mathrm{~mm}$ and a height of $200 \mathrm{~mm}$ (Figure 4(b)). Table 2 summarizes the specifications of the samples. The gravel 
TABLE 1: Basic physical properties of high plasticity soil.

\begin{tabular}{lcccccc}
\hline $\begin{array}{l}\text { Natural moisture } \\
\text { content (\%) }\end{array}$ & $\begin{array}{c}\text { Fine particle } \\
\text { content }(\%)\end{array}$ & $\begin{array}{c}\text { Liquid limit } \\
(\%)\end{array}$ & $\begin{array}{c}\text { Plastic limit } \\
(\%)\end{array}$ & $\begin{array}{c}\text { Plasticity } \\
\text { index }\end{array}$ & $\begin{array}{c}\text { Optimum moisture } \\
\text { content }(\%)\end{array}$ & $\begin{array}{c}\text { Maximum dry density } \\
\left(\mathrm{g} / \mathrm{cm}^{3}\right)\end{array}$ \\
\hline 29.1 & 60.3 & 54.0 & 28.5 & 25.5 & 17.3 & 1.76 \\
\hline
\end{tabular}

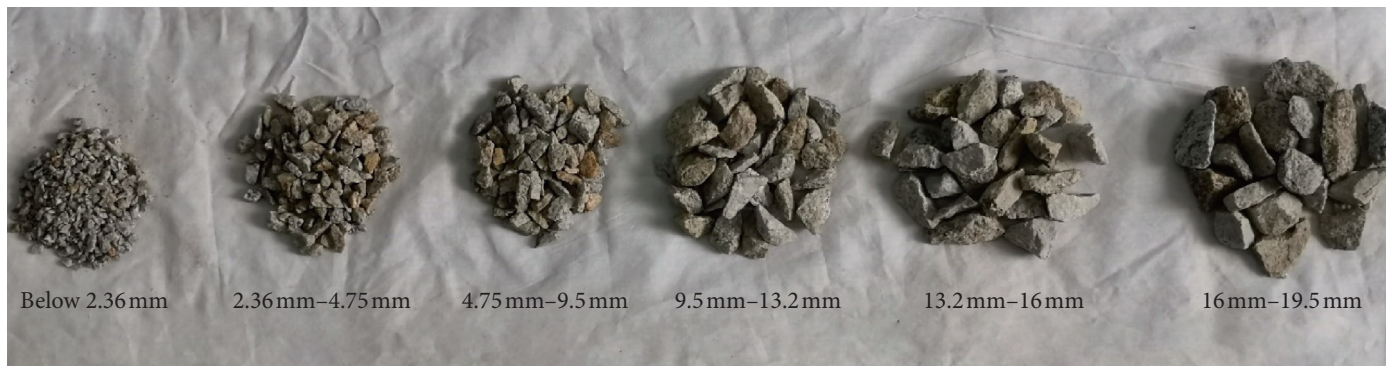

Figure 1: Photograph of different grain groups in the gravel.

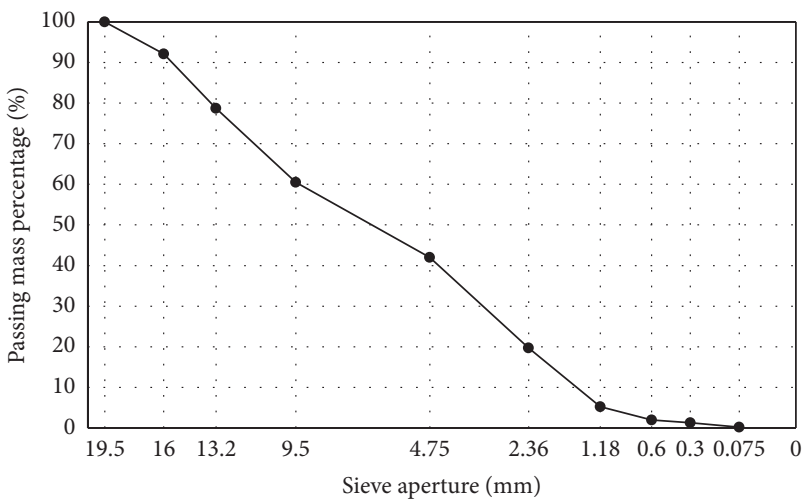

Figure 2: Gradation curve of the gravel.

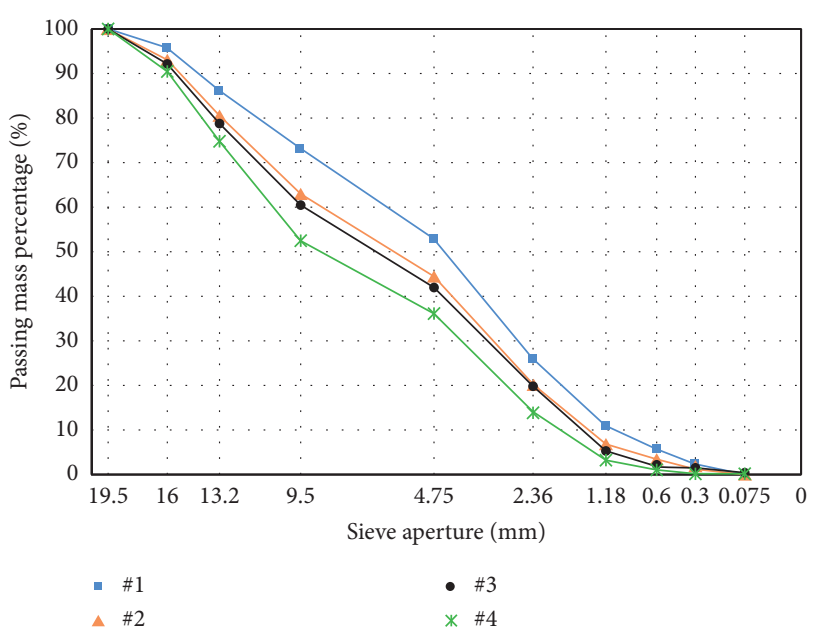

Figure 3: Four types of gravel gradation. Note that \#1, \#2, and \#4 are the upper, middle, and lower gradation types, respectively; \#3 is the gradation type shown in Figure 2.

volume ratio represents the ratio of gravel volume to total soil volume.

According to the Chinese code for the design of highway subgrades (JTG D30-2015), a half-sine wave load with a frequency of $1 \mathrm{~Hz}$ was used. The loading time was $0.1 \mathrm{~s}$ and the interval was $0.9 \mathrm{~s}$ [35]. To eliminate the plastic deformation of the sample, 1000 preloads were applied before testing. The specific loading sequence is shown in Table 3. For each sequence, the sample was loaded 100 times.

When the tests were completed, the axial recoverable strain amplitude of the last five cycles was selected, and thus the dynamic resilient modulus of each sample can be calculated [35]:

$$
M_{\mathrm{R}}=\frac{\sigma_{0}}{\varepsilon_{0}},
$$

where $\sigma_{0}$ is the axial stress amplitude; $\varepsilon_{0}$ is the axial recoverable strain amplitude; and $M_{\mathrm{R}}$ is the dynamic resilient modulus.

2.2.3. Tests of Voids in Coarse Aggregate. The structures of asphalt mixtures can be divided into the dense suspended structure and the dense skeleton structure. Considering the similarity between high plasticity soil-gravel mixtures and asphalt mixtures, one can determine the structure of the soilgravel mixtures by testing the voids in coarse aggregate following the skeleton analysis method for asphalt mixtures.

In this section, soil particles were divided into the coarse aggregate and the fine aggregate with the threshold size of $4.75 \mathrm{~mm}$. It was considered that the coarse aggregate played a skeleton role and the fine aggregate filled the voids in coarse aggregate. Thus, the soil packing structure was determined by comparing the voids in coarse aggregate of the compacted high plasticity soil-gravel mixture $\left(\mathrm{VCA}_{\text {mix }}\right)$ to those of the dry compacted coarse aggregate $\left(\mathrm{VCA}_{\mathrm{drc}}\right)$, as shown in Figure 5. If $\mathrm{VCA}_{\mathrm{mix}}>\mathrm{VCA}_{\mathrm{drc}}$, most of coarse aggregates cannot contact each other and are "suspended" in the mixture, so the soil mixture has the dense suspended structure (Figure 6(a)); if $\mathrm{VCA}_{\text {mix }} \leq \mathrm{VCA}_{\mathrm{drc}}$, most of coarse aggregates can contact each other to form a dense skeleton, so the soil mixture has the dense skeleton structure (Figure 6(b)).

The voids in coarse aggregate of the dry compacted coarse aggregate $\left(\mathrm{VCA}_{\mathrm{drc}}\right)$ are calculated as [36] 


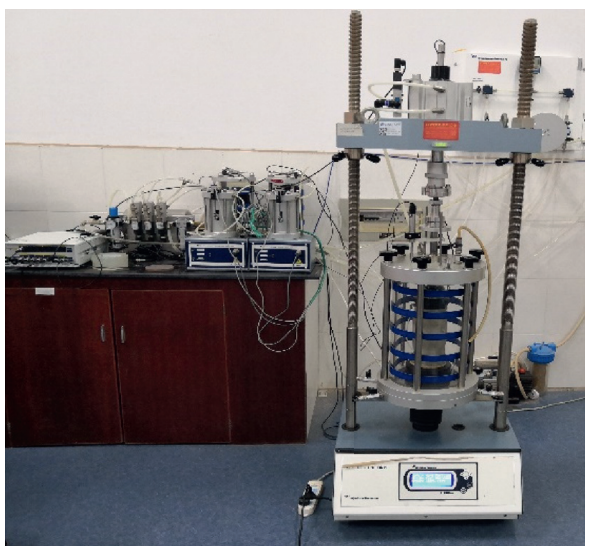

(a)

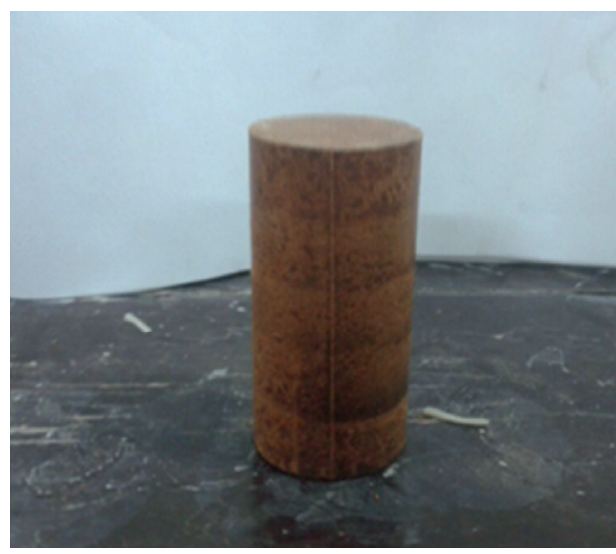

(b)

Figure 4: Dynamic triaxial tests. (a) Apparatus. (b) Prepared sample.

TABle 2: Specifications of the samples for dynamic triaxial sample tests.

\begin{tabular}{lccc}
\hline Gravel content (\%) & Gravel gradation type & Gravel volume ratio (\%) & Optimum moisture content (\%) \\
\hline 30 & $\# 3$ & 24.9 & 13.9 \\
35 & $\# 3$ & 28.1 & 13.6 \\
40 & $\# 3$ & 32.3 & 12.3 \\
45 & $\# 3$ & 36.1 & 12.7 \\
50 & $\# 1$ & 40.2 & 13.5 \\
50 & $\# 2$ & 40.2 & 13.3 \\
50 & $\# 3$ & 40.2 & 13.2 \\
50 & $\# 4$ & 40.2 & 13.0 \\
\hline
\end{tabular}

TABLE 3: Loading sequence for dynamic triaxial tests.

\begin{tabular}{lcccc}
\hline Loading sequence & Confining pressure $(\mathrm{kPa})$ & Cyclic stress $(\mathrm{kPa})$ & Vertical stress $(\mathrm{kPa})$ & Cycle number \\
\hline Preloading & 30 & 55 & 85 & 90 \\
1 & 60 & 30 & 75 & 1000 \\
2 & 45 & 30 & 60 & 100 \\
3 & 30 & 30 & 45 & 115 \\
4 & 15 & 30 & 100 & 100 \\
5 & 60 & 55 & 85 & 100 \\
6 & 45 & 55 & 70 & 135 \\
7 & 30 & 55 & 120 & 100 \\
8 & 15 & 55 & 105 & 100 \\
9 & 60 & 75 & 90 & 100 \\
10 & 45 & 75 & 105 & 100 \\
12 & 30 & 75 & 100 \\
13 & 15 & 105 & 105 & 100 \\
15 & 60 & 105 & 100 \\
\end{tabular}

$$
\mathrm{VCA}_{\mathrm{drc}}=\left(1-\frac{\gamma_{\mathrm{s}}}{\gamma_{\mathrm{ca}}}\right) \times 100,
$$

where $\gamma_{\mathrm{s}}$ is the relative bulk density of loose coarse aggregate; $\gamma_{\mathrm{ca}}$ is the relative bulk density of coarse aggregate [36]:

$$
\gamma_{c a}=\frac{P_{1}+P_{2}+\cdots+P_{n}}{\left(P_{1} / \gamma_{1}\right)+\left(P_{2} / \gamma_{2}\right)+\cdots+\left(P_{n} / \gamma_{n}\right)},
$$

where $P_{i}(i=1,2,3, \ldots, n)$ is the content of an aggregate fraction (see Figures 2 and 3$) ; \gamma_{i}(i=1,2,3, \ldots, n)$ is the relative bulk density of an aggregate fraction.

The voids in coarse aggregate of the high plasticity soilgravel mixture $\left(\mathrm{VCA}_{\mathrm{mix}}\right)$ are expressed as [36]

$$
\mathrm{VCA}_{\text {mix }}=\left(1-\frac{\gamma_{\mathrm{f}}}{\gamma_{\mathrm{ca}}} \times \frac{P_{\mathrm{ca}}}{100}\right) \times 100,
$$



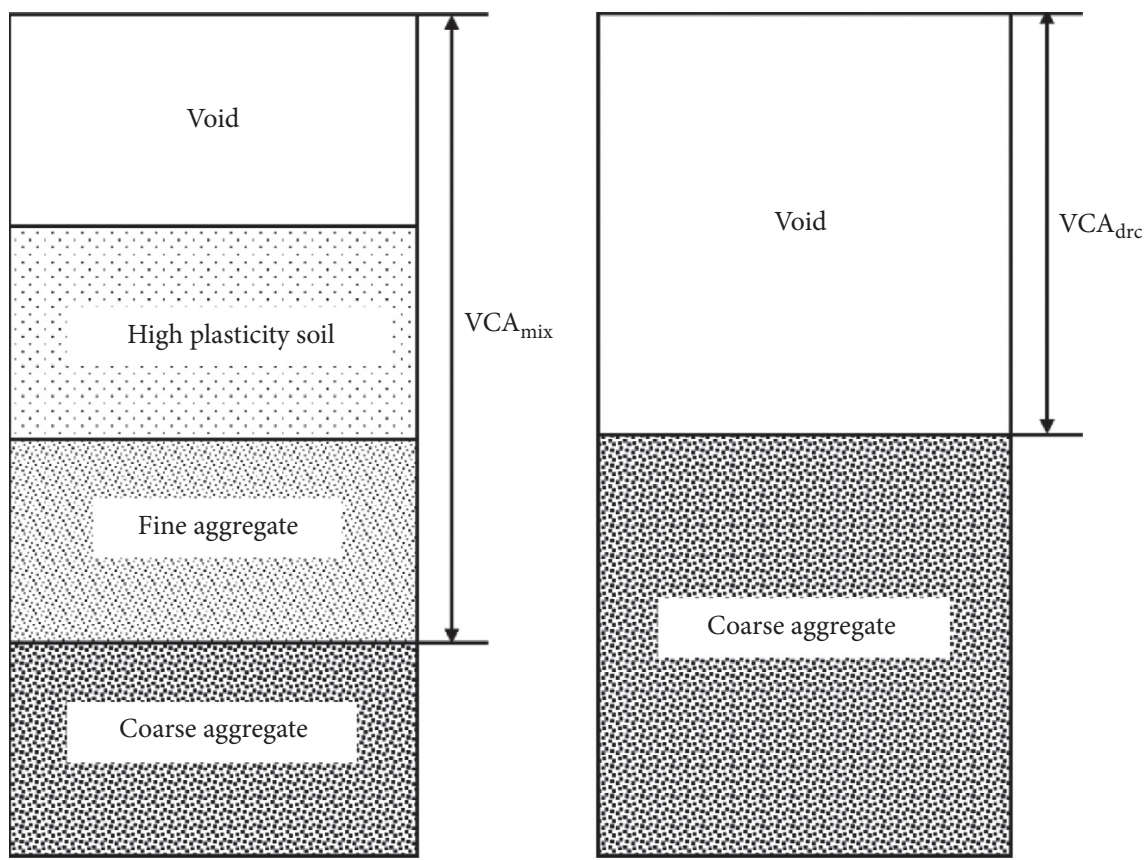

FIgURE 5: Schematic diagram of $\mathrm{VCA}_{\mathrm{drc}}$ and $\mathrm{VCA}_{\text {mix }}$.

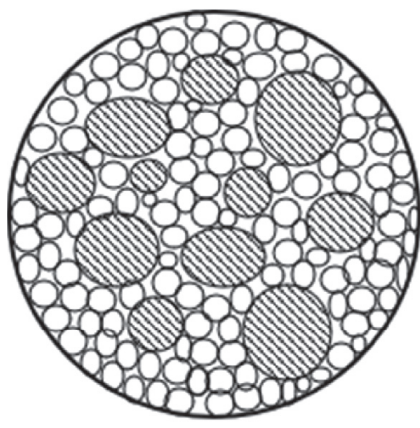

Coarse aggregate

$\bigcirc$ Fine aggregate and high plasticity soil

(a)

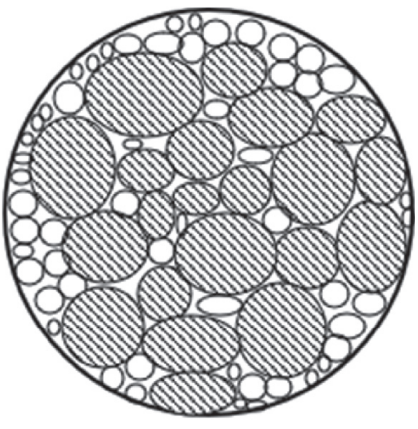

Coarse aggregate

Fine aggregate and high plasticity soil

(b)

FIGURE 6: Schematic diagram of the structure of soil-gravel mixtures. (a) Dense suspended structure. (b) Dense skeleton structure.

where $P_{\mathrm{ca}}$ is the content of coarse aggregates in the high plasticity soil-gravel mixture and $\gamma_{\mathrm{f}}$ is the relative bulk density of the high plasticity soil-gravel mixture, which can be determined using the wax sealing method as per the Chinese standard (JTG E20-2011) [37].

2.2.4. X-Ray CT Scan. The industrial YXLON X-ray CT scanner was used to detect the mesostructure of high plasticity soil-gravel mixtures, as shown in Figure 7. The samples were sealed during the scanning process to ensure that their moisture contents did not change. A voltage of $220 \mathrm{kV}$ and a current of $2.5 \mathrm{~mA}$ were utilized in X-ray CT scans after debugging [38].

A training step was conducted for 5 min by adjusting the upper limit voltage to $260 \mathrm{kV}$ before starting the instrument.

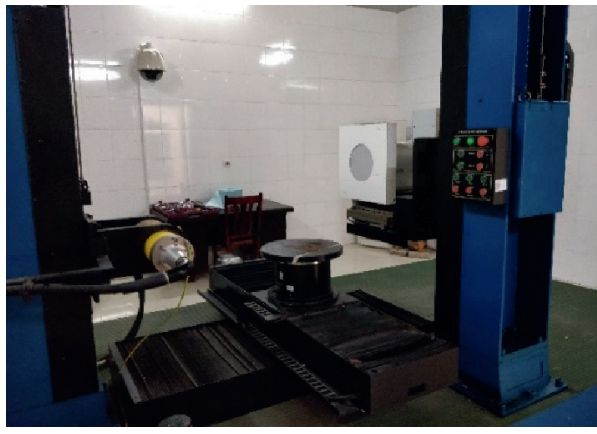

Figure 7: YXLON X-ray CT scanner.

Then, the position of the arm of the CT scanner was reset, and background data and gain data were corrected and entered by computer. Subsequently, the samples were placed 
on the test holder and scanned every $1 \mathrm{~mm}$ along the longitudinal direction. For each sample, 200 slices were obtained in total.

2.2.5. CT Image Processing. The AVIZO software was employed to process the CT images (Figure 8(a)). The image processing procedure mainly included two steps, i.e., preprocessing and segmentation. Image preprocessing consisted of voxel setting, boundary processing, image noise reduction, and particle recognition. The purpose of preprocessing was to remove image defects (e.g., artifact and noise), improve brightness and contrast, and identify particles. After preprocessing, white coarse grains, black void and background, and gray fine grains could be distinguished clearly (Figure 8(b)). The images were then further segmented to separate coarse grains to accommodate the subsequent particle contact analysis. In this study, the watershed segmentation method was selected for image segmentation after particle recognition, as shown in Figure 8(c).

\section{Results and Discussion}

3.1. Analysis of Dynamic Resilient Modulus. Table 4 and Figure 9 show that the gravel content and gravel gradation type have significant influences on the resilient modulus of high plasticity soil-gravel mixture samples. For the same gradation type, the modulus increases and the growth rate becomes larger with the increase in gravel content. When the gravel content is the same, as the gravel gradation changes from the upper to the lower type, the modulus increases. For example, the modulus of the sample with a gravel content of $50 \%$ and \#1-type (i.e., the upper type) gravel gradation is smaller than that of the sample with a gravel content of $45 \%$ and \#3-type gravel gradation. The specific mechanism can be explored from macroscopic and mesoscopic perspectives by testing the voids in coarse aggregate and analyzing CT images.

3.2. Analysis of Voids in Coarse Aggregate. Figure $10 \mathrm{com}-$ pares the voids in coarse aggregate of dry compacted coarse aggregates $\left(\mathrm{VCA}_{\mathrm{drc}}\right)$ and those of the compacted high plasticity soil-gravel mixture $\left(\mathrm{VCA}_{\text {mix }}\right)$.

It is observed that, with the increase in gravel content, $\mathrm{VCA}_{\text {mix }}$ of high plasticity soil-gravel mixture decreases. When the gravel content is less than $44.1 \%, \mathrm{VCA}_{\text {mix }}>\mathrm{VCA}_{\mathrm{drc}}$, and thus most of coarse aggregates are suspended in the soil. In this case, there are not enough contacts for coarse aggregates to form the skeleton structure. In other words, the sample shows a dense suspended structure. As a result, the resilient modulus increases slowly. When the gravel content is greater than $44.1 \%, \mathrm{VCA}_{\mathrm{drc}} \geq \mathrm{VCA}_{\text {mix }}$. In this case, most of coarse aggregates can contact each other to form a dense skeleton. With the increase in gravel content, the skeleton structure is constantly improved. Consequently, the growth of resilient modulus appears a faster trend.

The resilient moduli of the samples with different gravel gradation types are different even if their gravel contents are the same. When the soil has the upper type gradation, $\mathrm{VCA}_{\text {mix }}>\mathrm{VCA}_{\mathrm{drc}}$; thus, coarse aggregates are insufficient and suspended in the soil. This means that the soil belongs to the dense suspended structure. For this reason, the modulus is relatively low. This also explains why the modulus of the sample with a gravel content of $50 \%$ and \#1-type gravel gradation is lower than that of the sample with a gravel content of $45 \%$ and \#3-type gravel gradation. When the gravel gradation type changes from the middle to the lower type, the content of coarse aggregates gradually increases and coarse aggregates tend to contact each other to form an increasingly dense skeleton. Therefore, the soil changes from a dense suspended structure to a dense skeleton structure, and the modulus increases accordingly.

The structure has an important influence on the resilient modulus of soil. In the dense skeleton structure, the content of coarse aggregates is large, and coarse aggregates contact each other to form the skeleton structure. Due to the high stiffness of coarse aggregates themselves, the skeleton structure formed by coarse aggregates can well resist the external force with small deformations, and thus the soil shows a higher modulus. In the dense suspended structure, most of coarse aggregates are isolated and cannot effectively reinforce the soil, so the modulus is relatively low. If the structure type does not change, the modulus increases slowly with the increase in the content of coarse aggregates.

The gravel content and gravel gradation type affect the soil structure. The structure of the soil depends on the contents of coarse aggregates and fine aggregates. The specific performance is as follows: when the content of fine aggregates is large, fine aggregates will isolate coarse aggregates so that the latter cannot contact each other to form a skeleton. Thus, coarse aggregates are suspended in the soil, and the soil shows a dense suspended structure. With the increase in the content of coarse aggregates, coarse aggregates gradually contact each other to form a skeleton structure, and fine aggregates fill the voids in coarse aggregate tightly. Then, the soil structure changes from the dense suspended structure to the dense skeleton structure.

Therefore, the gravel content and gravel gradation type change the gradation of high plasticity soil-gravel mixture. A proper increase of the content of coarse aggregates can help the soil form a dense skeleton structure, thus improving the resilient modulus of high plasticity soil-gravel mixture.

3.3. Analysis of Contact Number. The structural stability of high plasticity soil-gravel mixture depends on the contacts between coarse aggregates. The contact state and contact degree of coarse aggregates also objectively reflect the compactness and the degree of interlocking of the soil. The tests of voids in coarse aggregate evaluate the structure of high plasticity soil-gravel mixture from a macroscopic perspective, but it is not possible to visualize the contact state of coarse aggregates inside the mixture. This section examines the contact state of coarse aggregates in the soil mixture based on the results of X-ray CT scans.

Figures 11 and 12 show the CT images of high plasticity soil-gravel mixtures. It is noted that when the gravel content 


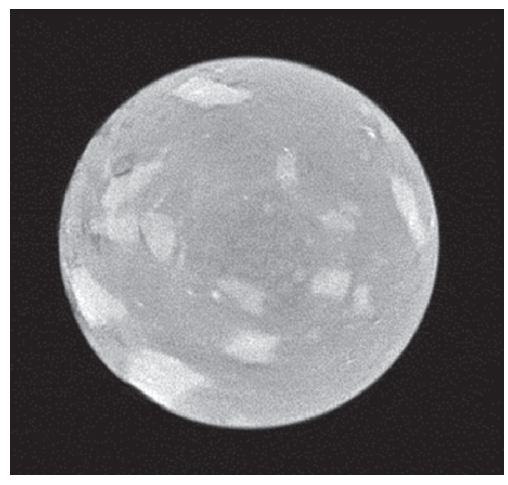

(a)

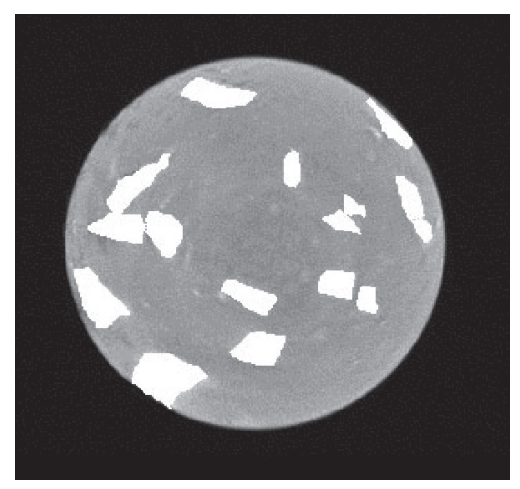

(b)

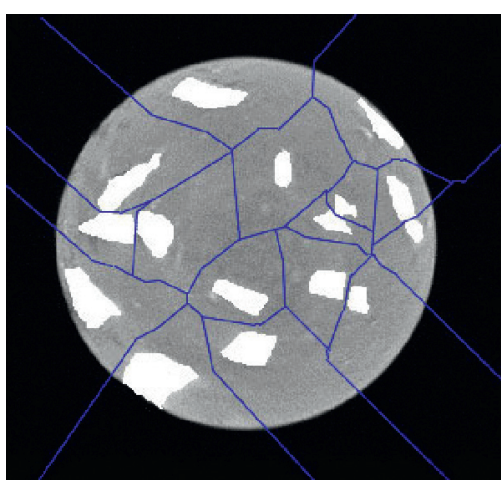

(c)

FIgURE 8: Processing of CT images. (a) Original image. (b) Preprocessing. (c) Segmentation.

TABLe 4: Results of dynamic triaxial tests.

\begin{tabular}{lcccc}
\hline Gravel content (\%) & Gravel gradation type & Gravel volume ratio (\%) & Measured moisture content (\%) & Dynamic resilient modulus (MPa) \\
\hline 30 & $\# 3$ & 24.9 & 14.2 & 58.2 \\
35 & $\# 3$ & 28.1 & 14.3 & 66.2 \\
40 & $\# 3$ & 32.3 & 12.2 & 76.9 \\
45 & $\# 3$ & 36.1 & 12.4 & 94.4 \\
50 & $\# 1$ & 40.2 & 13.7 & 88.4 \\
50 & $\# 2$ & 40.2 & 13.5 & 106.4 \\
50 & $\# 3$ & 40.2 & 13.4 & 108.8 \\
50 & $\# 4$ & 40.2 & 13.2 & 117.6 \\
\hline
\end{tabular}

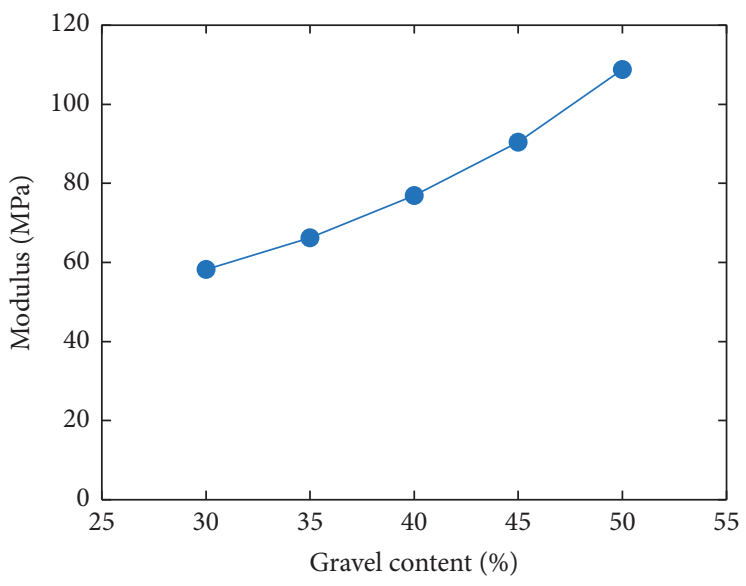

(a)

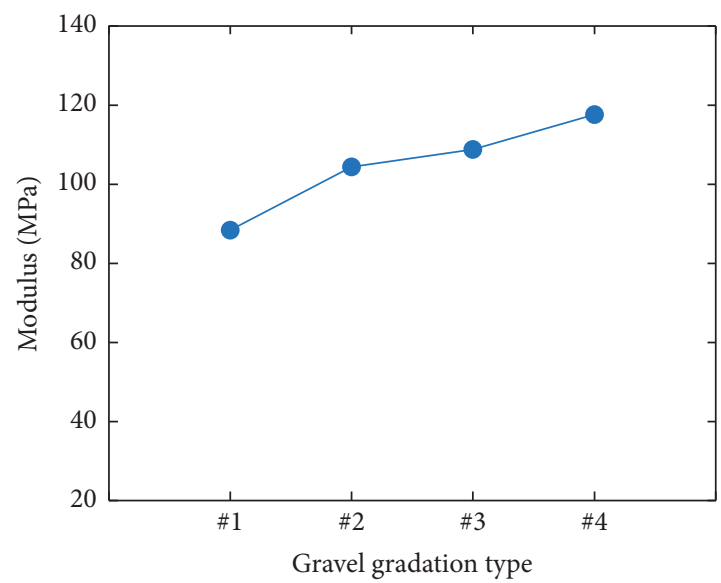

(b)

Figure 9: Dynamic resilient moduli of different samples affected by gravel content and gravel gradation type. (a) Different gravel contents and \#3-type gravel gradation. (b) Different gravel gradation types and 50\% gravel content.

is small, the number of contacts between coarse aggregates is less, and coarse aggregates are basically suspended in the soil. When the gravel content is large, coarse aggregates are close to each other and the number of "free" coarse aggregates is small, showing a large number of contact points. This indicates that coarse aggregates are interlocked to form a relatively stable skeleton structure.

As the gravel gradation changes from the upper to the lower type, the mean distance between coarse aggregates decreases and the number of contacts between coarse aggregates increases. As a result, the soil gradually forms an increasingly stable skeleton structure.

Figures 13 and 14 present the contact number of different samples along the height. It is observed that the contact number of coarse aggregates in the mixture is not uniform along the height direction. Generally, the number of contact points is larger in the lower part and less in the upper part of each sample. This is because the sample was formed by static compaction, which makes coarse aggregates gather in the middle and lower parts. Consequently, the contact 


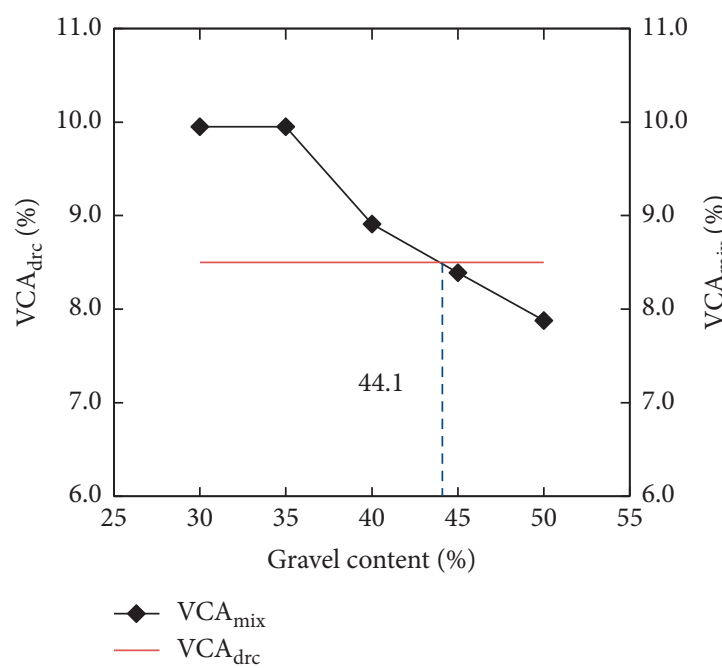

(a)

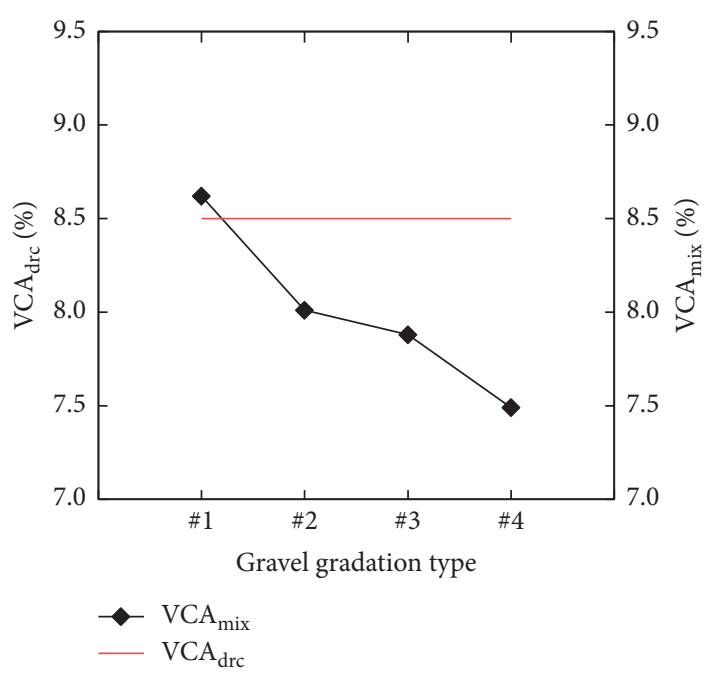

(b)

FIGURE 10: $\mathrm{VCA}_{\mathrm{drc}}$ and $\mathrm{VCA}_{\text {mix }}$ of different samples affected by gravel content and gravel gradation type. (a) Different gravel contents and \#3-type gravel gradation. (b) Different gradation types and 50\% gravel content.

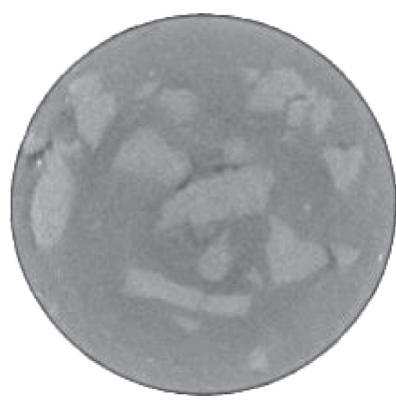

(a)

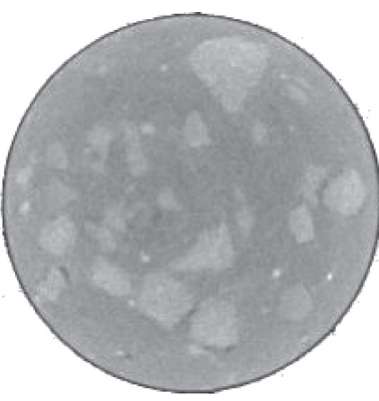

(b)

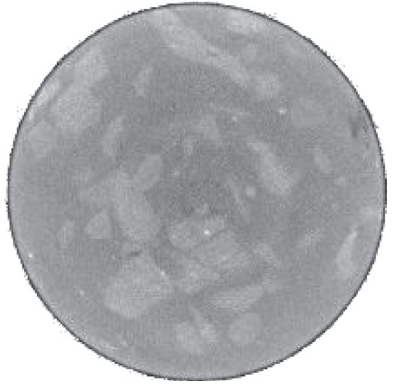

(c)

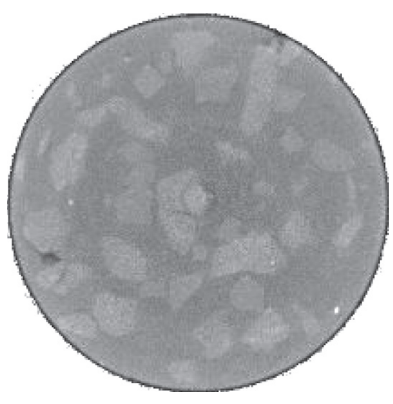

(d)

Figure 11: CT images of samples with \#3-type gravel gradation and different gravel contents: (a) 30\%, (b) 35\%, (c) 40\%, and (d) 45\%.

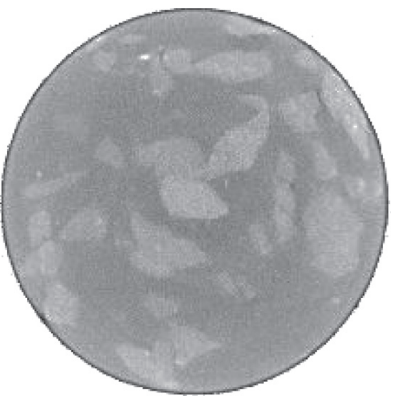

(a)

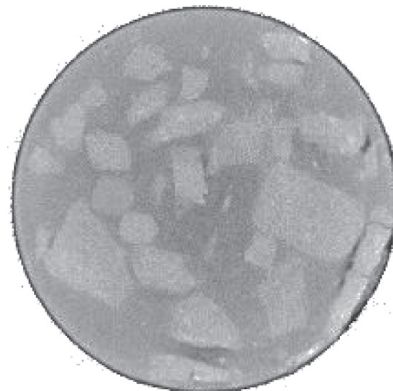

(b)

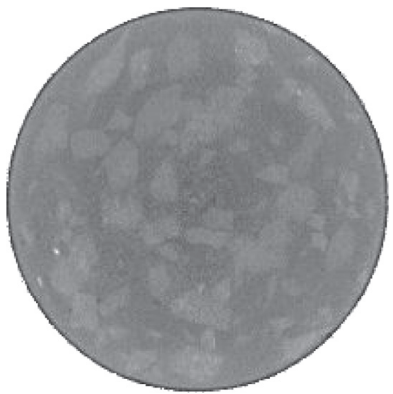

(c)

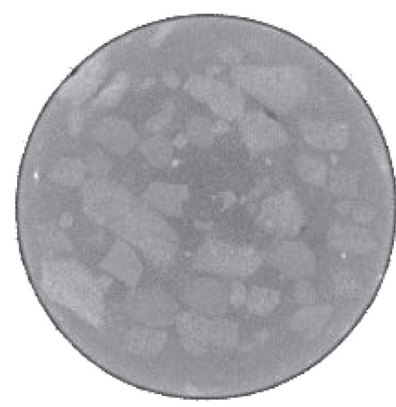

(d)

Figure 12: CT images of samples with 50\% gravel content and different gravel gradation types: (a) type \#1, (b) type \#2, (c) type \#3, and (d) type \#4.

number in the middle and lower parts is larger than that in the upper part. With the increase in gravel content, the fluctuation range of contact number also increases.

When the gravel content changes from $30 \%$ to $40 \%$, the number of contact points shows a slow increase. However, when the gravel content changes from $45 \%$ to $50 \%$, the number of contact points increases faster. The variation trend of the number of contact points is consistent with those of the resilient modulus and voids in coarse aggregates as the gravel content increases, as shown in Figures 9(a) and 10 (a).

When the gravel content is less than $44.1 \%$, $\mathrm{VCA}_{\text {mix }}>\mathrm{VCA}_{\mathrm{drc}}$, and most of coarse aggregates are suspended in the soil. The contact points between coarse aggregates are less. 


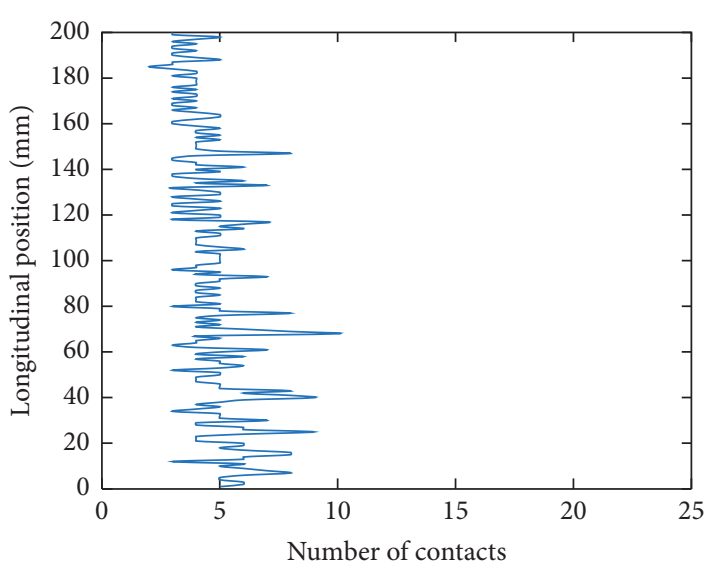

(a)

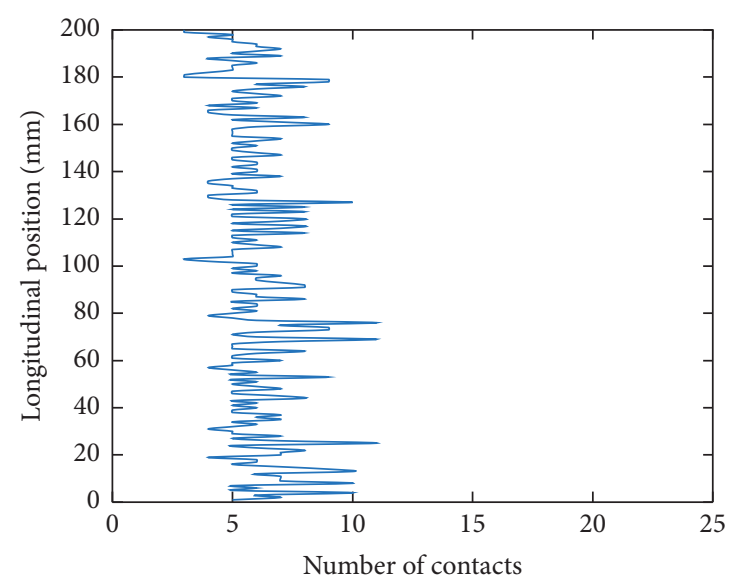

(c)

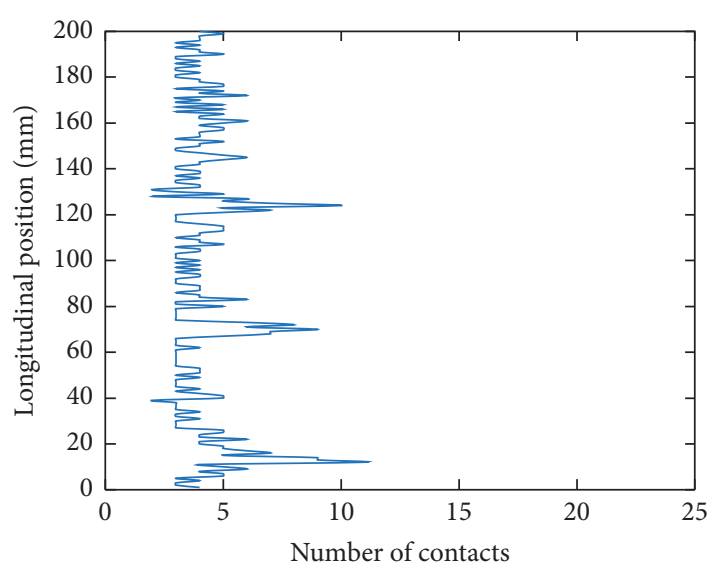

(b)

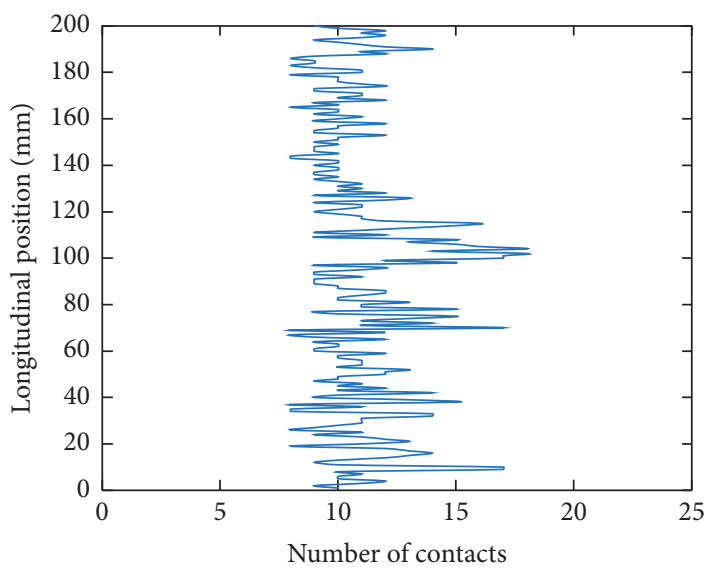

(d)

Figure 13: Contact number of the samples with different gravel contents and \#3-type gravel gradation. (a) Gravel content $=30 \%$. (b) Gravel content $=35 \%$. (c) Gravel content $=40 \%$. (d) Gravel content $=45 \%$.

The increase of contact number with the gravel content is slower, and the resilient modulus increases at a smaller rate accordingly. When the gravel content is more than $44.1 \%, \mathrm{VCA}_{\text {mix }}<\mathrm{VCA}_{\mathrm{drc}}$, and the skeleton structure begins to form among coarse aggregates. With the increase in gravel content, the contact number increases rapidly and the structure is continuously improved. Consequently, the resilient modulus increases rapidly.

Similarly, from the analysis of Figures 9(b), 10(b), and 14 , one can note that when the gravel gradation changes from the upper to the lower type, the contact number of coarse aggregates increases and coarse aggregates gradually form a strong skeleton. Thus, the resilient modulus increases accordingly.

Table 5 summarizes the number of contact points between coarse aggregates of different sizes. It is noted that when the gravel content is $30 \%-40 \%$, the number of contacts between coarse aggregates of each size is less and not all go up with the increase in gravel content. When coarse aggregates are suspended in the soil, they have less chance to contact each other, and thus the resilient modulus increases slowly as the gravel content increases. When the gravel content is $45 \%-50 \%$, interlocking is likely to happen between coarse aggregates, causing the formation of gravel skeleton. The number of contact points between coarse aggregates with different sizes goes up obviously. With the increase in gravel content, the number of coarse aggregates of each size increases; the chance of contact between each other increases. Therefore, the contact number and the resilient modulus increase.

When the gravel gradation approaches the lower type, coarse aggregates gradually form a skeleton. As the content of coarse aggregates increases, the number of contact points between coarse aggregates with different sizes generally increases and the resilient modulus increases accordingly. However, the number of contact points between coarse aggregates with different sizes in the sample with a gravel content of $50 \%$ and \#1-type gravel gradation is mostly smaller than that of the sample with a gravel content of $45 \%$ and \#3-type gravel gradation. This is why the modulus of the former is also smaller than that of the latter.

The difference in gravel content and gravel gradation type can alter the gradation of high plasticity soil-gravel mixture, which further leads to the change of contact number of coarse aggregates at the mesoscopic level. Consequently, the resilient modulus of high plasticity soilgravel mixture varies. When the content of coarse aggregates 


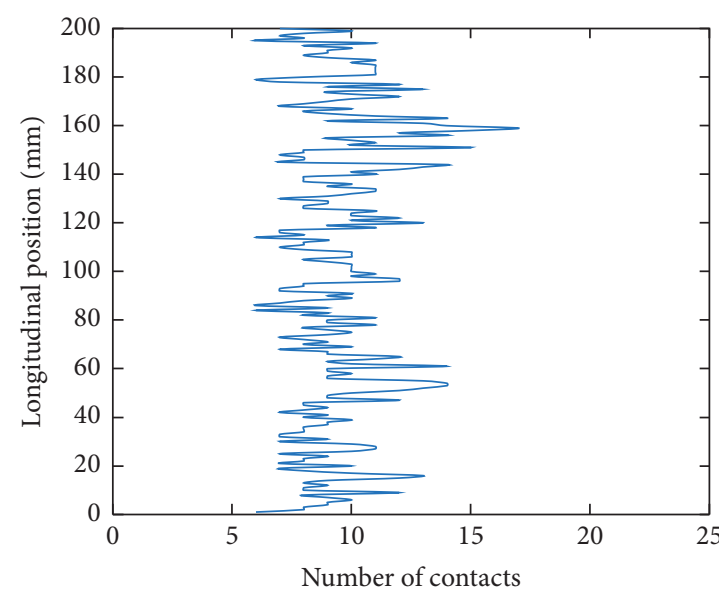

(a)

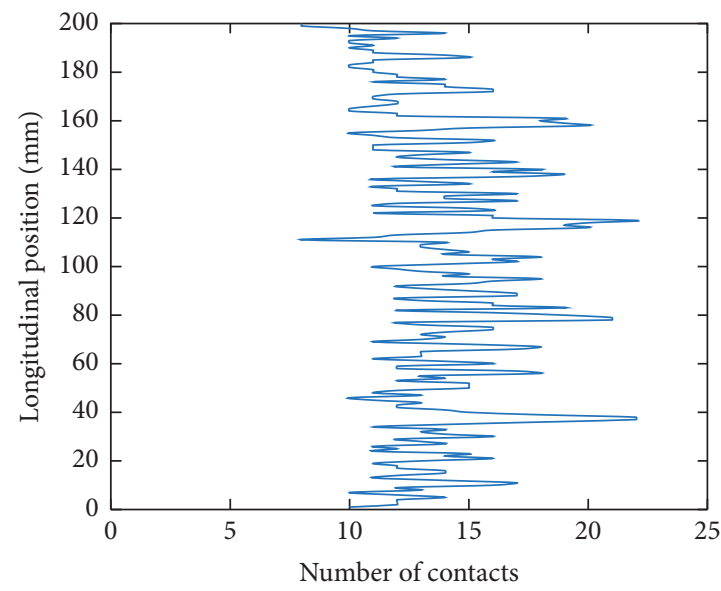

(c)

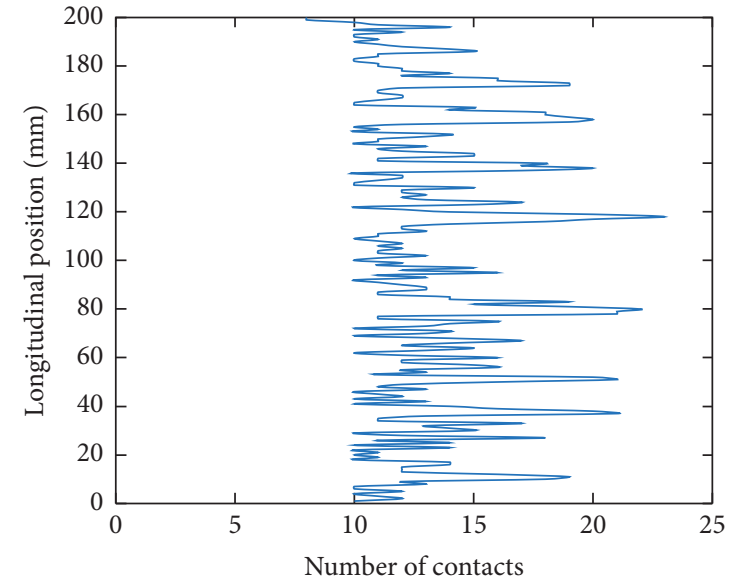

(b)

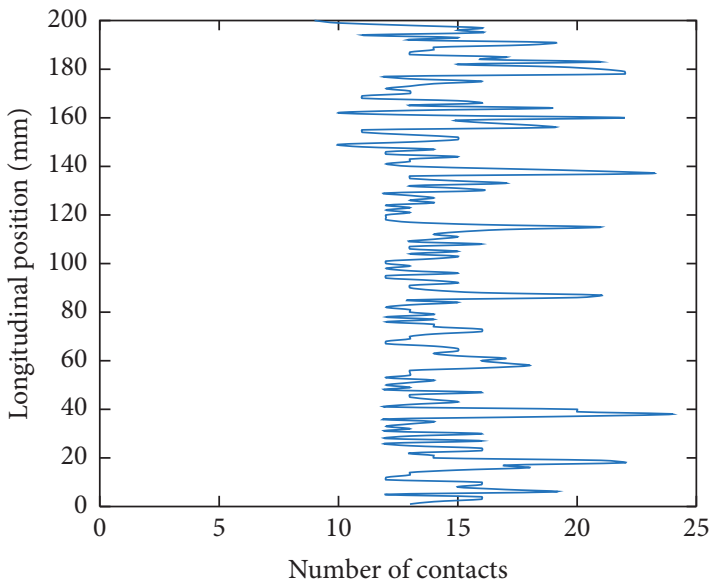

(d)

Figure 14: Contact number of the samples with different gravel gradation types and 50\% gravel content. (a) Type \#1. (b) Type \#2. (c) Type \#3. (d) Type \#4.

TABLE 5: Number of contact points between coarse aggregates of different sizes.

\begin{tabular}{|c|c|c|c|c|c|c|c|c|}
\hline \multirow{3}{*}{ Grain size } & \multicolumn{8}{|c|}{ Factor } \\
\hline & \multicolumn{4}{|c|}{ Gravel content } & \multicolumn{4}{|c|}{$\begin{array}{c}\text { Gravel gradation } \\
\text { type }\end{array}$} \\
\hline & $30 \%$ & $35 \%$ & $40 \%$ & $45 \%$ & $\# 1$ & $\# 2$ & \#3 & $\# 4$ \\
\hline $4.75 \mathrm{~mm}-4.75 \mathrm{~mm}$ & 48 & 57 & 39 & 123 & 177 & 218 & 225 & 253 \\
\hline $4.75 \mathrm{~mm}-9.5 \mathrm{~mm}$ & 98 & 90 & 102 & 155 & 195 & 284 & 296 & 311 \\
\hline $4.75 \mathrm{~mm}-13.2 \mathrm{~mm}$ & 41 & 70 & 66 & 169 & 163 & 254 & 266 & 271 \\
\hline $4.75 \mathrm{~mm}-16 \mathrm{~mm}$ & 39 & 35 & 32 & 152 & 142 & 211 & 245 & 242 \\
\hline $9.5 \mathrm{~mm}-9.5 \mathrm{~mm}$ & 134 & 188 & 317 & 374 & 299 & 390 & 398 & 410 \\
\hline $9.5 \mathrm{~mm}-13.2 \mathrm{~mm}$ & 170 & 146 & 219 & 396 & 286 & 398 & 402 & 414 \\
\hline $9.5 \mathrm{~mm}-16 \mathrm{~mm}$ & 93 & 98 & 112 & 153 & 133 & 232 & 244 & 279 \\
\hline $13.2 \mathrm{~mm}-13.2 \mathrm{~mm}$ & 130 & 129 & 127 & 294 & 236 & 325 & 330 & 374 \\
\hline $13.2 \mathrm{~mm}-16 \mathrm{~mm}$ & 53 & 85 & 133 & 154 & 164 & 176 & 194 & 212 \\
\hline $16 \mathrm{~mm}-16 \mathrm{~mm}$ & 18 & 32 & 47 & 96 & 89 & 136 & 147 & 130 \\
\hline
\end{tabular}

is large (e.g., the gravel content is large or the gravel gradation approaches the lower type), coarse aggregates are interlocked to form a skeleton structure. In this case, the soil has a larger resilient modulus.

\section{Case Study}

In order to better illustrate the influence of gradation on the resilient modulus of high plastic soil-gravel mixtures, a case study was carried out.

The Wanning-Yangpu expressway is $163 \mathrm{~km}$ long, located in Hainan Province, China. Approximately 2.4 million $\mathrm{m}^{3}$ high plasticity soils were excavated and used as filling materials for the subgrade construction.

The subgrade was divided into two parts. The lower part was the prepared roadbed, and the upper part included three layers. According to the Chinese specification for pavement design (JTG D50-2017), the comprehensive resilient modulus of the top surface of a subgrade should be not less than $120 \mathrm{MPa}$ [25]. Through in situ tests, the subgrade directly filled with high plasticity soil had a resilient modulus of 24.5 $\mathrm{MPa}$, which did not meet the standard.

Therefore, the high plasticity soil-gravel mixture was filled in the upper part to improve the overall modulus of the subgrade. The moduli of high plasticity soil-gravel mixtures with different gravel contents and gradation types are shown in Table 4 . The modulus of the mixture with a gravel content 


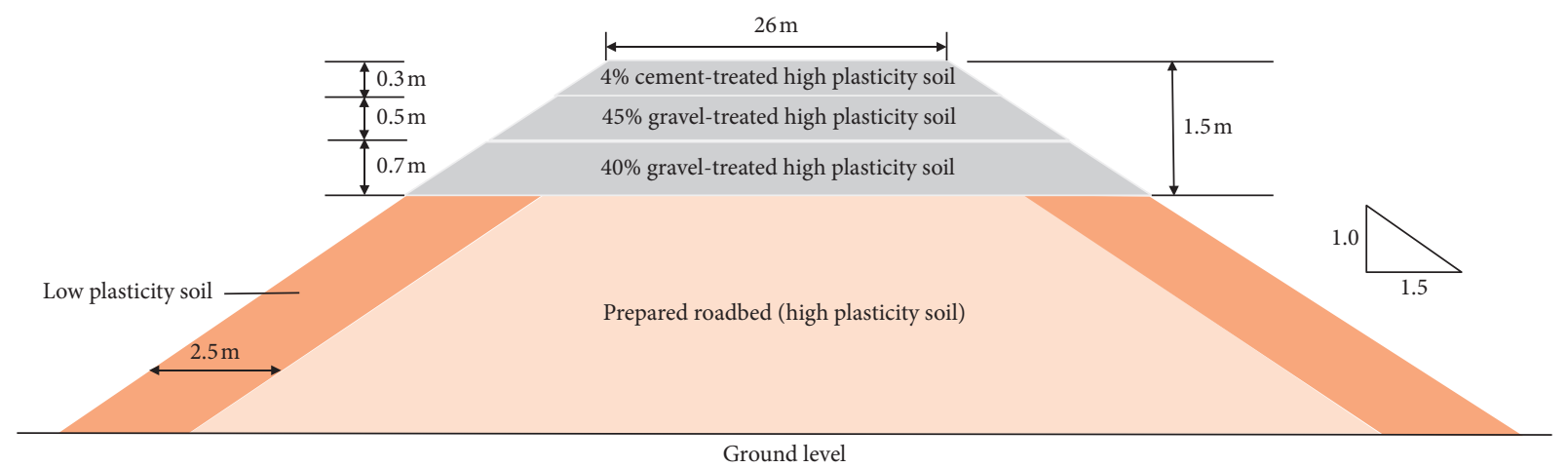

Figure 15: Cross section of treated subgrade.

of $30 \%$ or $35 \%$ is small, which has limited improvement effects on the overall modulus of the subgrade. Thus, the first layer and the second layer of the upper part were filled with high plasticity soils treated by $40 \%$ and $45 \%$ gravel (\#3-type gradation), respectively. Prior to compaction, the high plasticity soil-gravel mixture in each layer was blended by the WBZ21 road mixer (Shaanxi Construction Machinery, China) to make the mixture fully homogeneous. For the top layer of the upper part, the mixture with over 50\% gravel must be used to satisfy the design requirement, but the construction cost will be highly increased accordingly. Therefore, for the purpose of reducing costs, the top layer was filled with $4 \%$ cement-treated high plasticity soil instead. The cross section of the subgrade is shown in Figure 15. The in situ test results showed that the resilient modulus of the top surface of the subgrade was $169 \mathrm{MPa}$, which was larger than the required value (i.e., $120 \mathrm{MPa}$ ). The case study suggests that the desired gravel content is $40 \%-45 \%$ when the gravel mixing method is used to improve high plasticity soils.

\section{Conclusions}

In this study, the resilient modulus of high plasticity soilgravel mixture was obtained by dynamic triaxial tests. The structure of the soil mixture was determined by testing the voids in coarse aggregate. Moreover, the mesostructure of the soil-gravel mixture was analyzed using X-ray CT scans. The influence of gravel mixing on the resilient modulus of high plasticity soil-gravel mixture was analyzed considering different gravel contents and gravel gradation types. The following conclusions can be drawn:

(1) The resilient modulus of the mixture increases with the increase in gravel content and gradually increases as the gravel gradation approaches the lower type, suggesting that the gradation of high plasticity soilgravel mixture has a great influence on its resilient modulus.

(2) When the gravel content is less than $44.1 \%$, $\mathrm{VCA}_{\text {mix }}>\mathrm{VCA}_{\mathrm{drc}}$, and the resilient modulus increases slowly with increasing gravel content. When gravel content is greater than $44.1 \%, \mathrm{VCA}_{\text {mix }}<\mathrm{VCA}_{\mathrm{drc}}$, and the resilient modulus increases rapidly with increasing gravel content. The result indicates that $44.1 \%$ is a critical gravel content. As the gravel content exceeds this critical value, the modulus increases faster with the increase in gravel content.

(3) As the gravel gradation tends to the lower type, the quantity of coarse aggregates increases and the resilient modulus increases accordingly. As the gravel gradation approaches the upper type, coarse aggregates decrease in quantity and tend to suspend in the soil, so the modulus decreases.

(4) When the content of coarse aggregates is large, coarse aggregates are able to contact each other to form a skeleton. The dense skeleton structure is continuously improved with the increase in contact number. As a result, the soil shows a large resilient modulus.

(5) The contact analysis revealed that the fundamental reason for the improvement of the resilient modulus of the soil mixture is the increase in the number of contacts between coarse aggregates.

(6) The use of high plasticity soil-gravel mixtures with different gradations is effective in improving the resilient modulus of a road subgrade. This method can make rational use of high plasticity soil to reduce soil abandonment and construction costs. So, it is environmentally friendly and economical.

\section{Data Availability}

The data used to support the findings of this study are available from the corresponding author upon request.

\section{Conflicts of Interest}

The authors declare that there are no conflicts of interest regarding the publication of this paper.

\section{Acknowledgments}

This work was supported by the National Natural Science Foundation of China (51978085, 51108049, and 51708071) and Highway Industry Standard Compilation Project of Ministry of Transportation (JTG-201507). The experimental 
results in Tables 4-5 and Figures 13-14 were obtained with the help of Jia-Rui Yan and Jing-Xi Gong, both undergraduate students at Changsha University of Science \& Technology.

\section{References}

[1] R. Zhang, T. Z. Ren, M. D. Khan, Y. S. Teng, and J. L. Zheng, "Back-calculation of soil modulus from PFWD based on a viscoelastic model," Advances in Civil Engineering, vol. 2019, Article ID 1316341, , 2019.

[2] J. H. Zhang, L. Ding, F. Li, and J. H. Peng, "Recycled aggregates from construction and demolition wastes as alternative filling materials for highway subgrades in China," Journal of Cleaner Production, vol. 255, Article ID 120223, 2020.

[3] R. Zhang, Z. N. Liu, J. L. Zheng, and J. H. Zhang, "Experimental evaluation of lateral swelling pressure of expansive soil fill behind a retaining wall," Journal of Materials in Civil Engineering, vol. 32, no. 2, Article ID 04019360, 2020.

[4] J. James, "Sugarcane press mud modification of expansive soil stabilized at optimum lime content: strength, mineralogy and microstructural investigation," Journal of Rock Mechanics and Geotechnical Engineering, vol. 12, no. 2, pp. 395-402, 2020.

[5] Q. H. Wu, Q. Xu, and W. Y. Li, "Comparative study on improving high liquid limit clay as roadbed fillings in Chengdu area," Materials Research Innovations, vol. 19, no. 8, pp. 241-244, 2015.

[6] Z. Lei, "Experimental study on road properties of high liquid limit soil in Yunfu Highway," The Open Construction and Building Technology Journal, vol. 9, no. 1, pp. 46-51, 2015.

[7] Z. Lu, R. Fang, Y. X. Zhan, and H. L. Yao, "Study on the dynamic deformation of road high liquid limit subgrade soil," Advances in Civil Engineering, vol. 2019, Article ID 4084983, 7 pages, 2019.

[8] M. F. Lei, J. Y. Liu, Y. X. Lin, C. H. Shi, and C. Liu, "Deformation characteristics and influence factors of a shallow tunnel excavated in soft clay with high plasticity," Advances in Civil Engineering, vol. 2019, Article ID 7483628, , 2019.

[9] R. Zhang, M. X. Long, and J. L. Zheng, "Comparison of environmental impacts of two alternative stabilization techniques on expansive soil slopes," Advances in Civil Engineering, vol. 2019, Article ID 9454929, 2019.

[10] S. Guo, P. Gao, T. Cheng, and S. Long, "Determination of improvement method for high liquid limit soil," Advances in Science \& Technology of Water Resources, vol. 33, no. 6, pp. 52-55, 2013.

[11] A. Kumar and D. K. Soni, "Effect of calcium and chloride based stabilizer on plastic properties of fine grained soil," International Journal of Pavement Research and Technology, vol. 12, no. 5, pp. 537-545, 2019.

[12] Y. Que, Y. Q. Lin, and F. Z. Gong, "Experimental study on the performance of compound improved HLLS (high liquid limit soil) with various curing agents," Key Engineering Materials, vol. 753, pp. 300-304, 2017.

[13] W. H. Zhang, H. W. Zheng, J. W. Qi, and B. T. Wang, "Experimental study on the feasibility of using water glass and aluminum sulfate to treat complications in high liquid limit soil subgrade," Advances in Materials Science and Engineering, vol. 2015, Article ID 457978, 2015.

[14] A. K. Bera, "Effect of sand content on engineering properties of fine-grained soil mixed with sand," Electronic Journal of Geotechnical Engineering, vol. 16, pp. 1275-1286, 2011.
[15] F. M. Khan, S. Azam, M. E. Raghunandan, and R. Clark, "Compressive strength of compacted clay-sand mixes," Advances in Materials Science and Engineering, vol. 2014, Article ID 921815, 2014.

[16] H. Choo, W. Lee, and C. Lee, "Compressibility and small strain stiffness of kaolin clay mixed with varying amounts of sand," KSCE Journal of Civil Engineering, vol. 21, no. 6, pp. 2152-2161, 2017.

[17] H. Zhang, Y. Tan, F. Zhu, D. He, and J. Zhu, "Shrinkage property of bentonite-sand mixtures as influenced by sand content and water salinity," Construction and Building Materials, vol. 224, pp. 78-88, 2019.

[18] H. Rahardjo, T. T. Lim, M. F. Chang, and D. G. Fredlund, "Shear-strength characteristics of a residual soil," Canadian Geotechnical Journal, vol. 32, no. 1, pp. 60-77, 1995.

[19] M. K. Jafari and A. Shafiee, "Mechanical behavior of compacted composite clays," Canadian Geotechnical Journal, vol. 41, no. 6, pp. 1152-1167, 2004.

[20] Y. Guney, A. H. Aydilek, and M. M. Demirkan, "Geoenvironmental behavior of foundry sand amended mixtures for highway subbases," Waste Management, vol. 26, no. 9, pp. 932-945, 2006.

[21] J. H. Peng, J. H. Zhang, J. Li, Y. S. Yao, and A. S. Zhang, "Modeling humidity and stress dependent subgrade soils in flexible pavements," Computers and Geotechnics, vol. 120, Article ID 103413, 2020.

[22] X. Liu, X. Zhang, H. Wang, and B. Jiang, "Laboratory testing and analysis of dynamic and static resilient modulus of subgrade soil under various influencing factors," Construction and Building Materials, vol. 195, pp. 178-186, 2019.

[23] J. Zhang, F. Gu, and Y. Zhang, "Use of building-related construction and demolition wastes in highway embankment: laboratory and field evaluations," Journal of Cleaner Production, vol. 230, pp. 1051-1060, 2019.

[24] V. George and A. Kumar, "Studies on modulus of resilience using cyclic tri-axial test and correlations to PFWD, DCP, and CBR," International Journal of Pavement Engineering, vol. 19, no. 11, pp. 976-985, 2018.

[25] China Communications Press, JTG D50-2017 Specifications for Design of Highway Asphalt Pavement, China Communications Press, Beijing, China, 2017, in Chinese.

[26] J. Zhang, J. Peng, L. Zeng, J. Li, and F. Li, "Rapid estimation of resilient modulus of subgrade soils using performance-related soil properties," International Journal of Pavement Engineering, vol. 2019, no. 1, pp. 1-8, 2019.

[27] B. T. Nguyen and A. Mohajerani, "Possible estimation of resilient modulus of fine-grained soils using a dynamic lightweight cone penetrometer," International Journal of Pavement Engineerin, vol. 18, no. 6, pp. 473-484, 2017.

[28] J. Zhang, J. Peng, W. Liu, and W. Lu, "Predicting resilient modulus of fine-grained subgrade soils considering relative compaction and matric suction," Road Materials And Pavement Design, vol. 2019, no. 1, pp. 1-13, 2019.

[29] P. M. Reza and J. E. Haddock, "Determination of voids in the mineral aggregate and aggregate skeleton characteristics of asphalt mixtures using a linear-mixture packing model," Construction and Building Materials, vol. 188, pp. 292-304, 2018.

[30] N. M. Husain, M. R. Karim, H. B. Mahmud, and S. Koting, "Effects of aggregate gradation on the physical properties of semiflexible pavement," Advances in Materials Science and Engineering, vol. 2014, Article ID 529305, 2014.

[31] C. Xing, H. Xu, Y. Tan, X. Liu, and Q. Ye, "Mesostructured property of aggregate disruption in asphalt mixture based on 
digital image processing method," Construction and Building Materials, vol. 200, pp. 781-789, 2019.

[32] G. P. Hao, "Research on coarse aggregate gradation of SMA mixture influence with material properties," Advanced Materials Research, vol. 700, pp. 179-182, 2013.

[33] American Society for Testing and Materials, ASTM D2487-06 Standard Classification of Soils for Engineering Purposes (Unified Soil Classification System), American Society for Testing and Materials, West Conshohocken, PA, USA, 2006.

[34] L. J. Wang and H. Liu, "Method of aggregate gradation design of skeleton denseness asphalt mixture," China Journal of Highway and Transport, vol. 21, no. 5, pp. 6-9, 2008, in Chinese.

[35] China Communications Press, JTG D30-2015 Specifications for Design of Highway Subgrades, China Communications Press, Beijing, China, 2015, in Chinese.

[36] American Society for Testing and Materials, ASTM C29/ C29M-2017 Standard Test Method for Bulk Density and Voids in Aggregate, American Society for Testing and Materials, West Conshohocken, PA, USA, 2017.

[37] China Communications Press, JTG E20-2011 Standard Test Methods of Bitumen and Bituminous Mixtures for Highway Engineering, China Communications Press, Beijing, China, 2011, in Chinese.

[38] F. S. J. Martínez, M. A. Martín, F. J. Caniego et al., "Multifractal analysis of discretized X-ray CT images for the characterization of soil macropore structures," Geoderma, vol. 156, no. 1-2, pp. 37-42, 2010. 